This is an author produced version of a paper published in European Journal of Obstetrics \& Gynecology and Reproduction Biology. This paper has been peerreviewed but does not include the final publisher proof-corrections or journal pagination.

Citation for the published paper:

Starck M, Bohe M, Valentin L.

"Effect of vaginal delivery on endosonographic anal sphincter morphology" European Journal of Obstetrics \& Gynecology and Reproduction Biology, 2006, Issue: May 17.

http://dx.doi.org/10.1016/j.ejogrb.2006.04.009

Access to the published version may require journal subscription. Published with permission from: Elsevier 
Effect of vaginal delivery on endosonographic anal sphincter morphology

Marianne Starck $^{\mathrm{a},{ }^{*}}$, Måns Bohe ${ }^{\mathrm{a}}$ and Lil Valentin ${ }^{\mathrm{b}}$

${ }^{\mathrm{a}}$ Department of Surgery, Malmö University Hospital, Lund University, Malmö, Sweden

${ }^{\mathrm{b}}$ Department of Obstetrics and Gynecology, Malmö University Hospital, Lund University, Malmö, Sweden

* Corresponding author: Tel.: (+46) 40-333768; Fax: (+46) 40-927877.

E-mail adress: mariann.starck@skane.se 


\title{
Effect of vaginal delivery on endosonographic anal sphincter morphology
}

\begin{abstract}
Objective: To describe the effect of vaginal delivery with no clinically recognized sphincter tear on endosonographic anal sphincter morphology and sphincter pressure and to relate endosonographic results to anal sphincter pressure and anal incontinence score.
\end{abstract}

Study design: Thirty-two nullipara underwent anal endosonography and anal manometry in the third trimester of pregnancy, 2 weeks and 6 months post-partum. The sphincter defect scores (1-16) and the thickness and length of the sphincters were measured by endosonography, and sphincter pressures and manometric sphincter lengths were determined. The Wexner incontinence score (1-20) was used to classify anal incontinence 6 months post partum.

Results: Five (16\%) women had small endosonographic anal sphincter defects (score 3 - 4) before delivery. Eight women (25\%; confidence interval 11 - 43\%) had new defects detected post partum, five small, one moderate (score 7), and two large (score 10 - 11). Six (75\%) of eight women with new defects post-partum had undergone episiotomy vs. five (21\%) of 24 women with no new defects ( $p=0.02)$. Six months after delivery 16 (50\%) women reported anal incontinence, and there was a positive correlation between the endosonographic defect score 6 months post partum and the Wexner incontinence score. The sphincter was significantly longer during pregnancy than 6 months post partum.

Conclusion: New sphincter defects may arise after vaginal delivery without any clinically recognizable sphincter tear. There is a positive correlation between the endosonographic defect score 6 months post partum and the Wexner incontinence score.

Key words: Ultrasonography; anal sphincter defects; vaginal delivery; anal incontinence 


\section{Introduction}

Anal sphincter defects are often seen at anal endosonography after primary repair of a third degree perineal laceration $(1,2)$. This raises the question whether the repair was adequate. After a vaginal delivery without a clinically recognised sphincter tear, endosonographic sphincter defects have been observed with a frequency of 7\% to $41 \%$ (3-11). We have found $20 \%$ (5/25) of non-pregnant nullipara with no symptoms of anal incontinence to have sphincter defects at anal endosonography. Most of these defects were small, but some were large (12). Such defects may be a normal variant or the result of unknown trauma.

Endosonographic sphincter defects are not always associated with anal incontinence (4-6, 811). There are conflicting reports with regard to a possible association between sphincter defects and the results of anal manometry (3-5,7-11). We have introduced an endosonographic sphincter defect score to describe the extension of sphincter defects (2). The use of this scoring system facilitates the study of a possible association between the size of endosonographic sphincter defects and sphincter pressure and anal incontinence.

A few studies have examined a possible effect of vaginal delivery on anal canal anatomy in the absence of known sphincter trauma (13-15). Sultan and colleges (13) found vaginal delivery to have no substantial effect on anal sphincter morphology, whereas Frudinger and coworkers (14) reported a significant anterior thinning of the external sphincter after vaginal delivery, and Williams and colleges (15) found a shortening of the anterior external anal sphincter.

The aims of this study were 1) to describe the effect of vaginal delivery with no clinical signs of anal sphincter tear on endosonographic morphology of the anal sphincter and on anal sphincter pressure, and 2) to relate endosonographic results to anal sphincter pressure and symptoms of anal incontinence. 


\section{Material and methods}

The ethics committee of the Medical Faculty, Lund University, Sweden approved the study. Written consent was obtained from all the participants after the procedures had been explained to them in detail.

\section{2:1 Study design}

During a17-month period (December1998 to May 2000), consecutive pregnant nulliparous volunteers at two antenatal clinics of Malmö University Hospital, Sweden, were asked to participate in our study. Women with a history of anal surgery, anorectal dysfunction, or a medical condition that might preclude vaginal delivery were not eligible. The women were informed that if they would be delivered by caesarean section or if they would sustain a sphincter tear during vaginal delivery they would be excluded from the study.

The women included underwent anal endosonography and anal manometry in the third trimester, and then 2 weeks and 6 months post-partum. They were examined in the left lateral position. Anal manometry was performed immediately before the endosonographic examination, the manometry being performed by a laboratory technician and the ultrasound examination by the first author. The clinical details of each patient's delivery were unknown to the examiners. At the 6-month follow-up examination the women answered a questionnaire with regard to anal incontinence.

\section{2:2 Subjects}

Forty-seven nullipara underwent anal manometry and endosonography in the third trimester. Thirty-three women were re-examined 2 weeks post-partum, and 32 women underwent all three examinations. These 32 women are included in our study and underwent their first examination at a mean of 37 gestational weeks \pm 1.3 SD (SD, standard deviation), range 34 38. Their mean age was 29 years \pm 4.1 . Fourteen women were only examined in the third trimester for the following reasons: seven women declined post-partum examination, five 
women were delivered by caesarean section, and two women sustained an anal sphincter tear. One woman declined to undergo the third examination. Out of the seven women who declined post-partum examination, five had a spontaneous vaginal delivery (one with episiotomy) and one was delivered by vacuum extraction and episiotomy.

\section{2:3 Anal endosonography}

The women were scanned with a B-K Leopard 2001 system (B-K Medical, Herlev, Denmark) with a Type 1850 endoprobe and a 10-MHz frequency rotating transducer (B-K 6004) covered with a waterfilled sonolucent plastic cone with a diameter of $12 \mathrm{~mm}$. The cone was covered with a condom. The cone was inserted into the anal canal. The internal sphincter is seen as a homogenous, hypoechoic ring immediately beneath the anal mucosa (Figure 1a). The longitudinal muscle and the external sphincter have mixed echogenicity (Figure 1a). The 12 o'clock position of the endosonographic image was anterior.

When searching for sphincter defects the observer manually withdrew the transducer at low speed from the puborectalis level through the anal canal to the anal opening. The thickness of the internal and external anal sphincter was measured in the midanal canal at positions corresponding to 12, 3, 6 and 9 o'clock by using electronic callipers on the frozen ultrasound image. Mean sphincter thickness was the mean of the four measurements.

The endosonographic length of the anal canal was determined by mounting the endoprobe on a step-unit (B-K Medical, Herlev, Denmark, step-unit UA 651) which moves the endoprobe in $5 \mathrm{~mm}$ steps. Two measurements were taken, the first one with the probe moving downwards from the level where the puborectalis muscle is clearly defined to the anal verge, the second one with the probe moving upwards from the anal verge to the puborectalis muscle. The endosonographic length of the anal canal was defined as the mean of these two measurements. Two endosonographic lengths were measured: one from the puborectalis muscle to the anal verge (posterior length) and one from the anterior upper end of the external 
sphincter to the anal verge (anterior length). The difference between the posterior and the anterior length was also calculated. The thickness of the internal and external sphincters and the length of the sphincters were measured on-line, but the examinations were also recorded on Super-VHS videotapes. After completion of the study, the ultrasound examiner reviewed the videotapes and revised the measurements of the sphincter thickness by checking the position of the electronic callipers and changing the measurements of the thickness if they were judged to be incorrect. Eight percent (70/896) of the on-line measurements were changed at revision. Most corrections were made at the 12 o'clock position of the external sphincter.

Sphincter defects were measured and classified off-line twice at a time interval of 1-3 weeks. The second evaluation was done without knowledge of the results of the first evaluation. Any intra-observer disagreement was resolved at a third evaluation by the same observer (MS) a few days after the second evaluation. All evaluations were done without knowledge of the results of previous or subsequent examinations in the same woman.

An endosonographic sphincter defect was defined as a discontinuity in the endosonographic image of the internal or external sphincter. Defects engaging less than half of the external sphincter thickness and/or less than half of the internal sphincter thickness were not classified as defects, those engaging at least half but not the whole sphincter thickness were classified as partial defects, and those engaging the whole sphincter thickness were classified as total defects. The location and size of any sphincter defect were described using a clockwork symbol with the 12 o'clock position anteriorly, the defect being described to extend clockwise. In addition, the longitudinal location and extension of any sphincter defect were described (i.e., at least half of the sphincter length, more than half but not the whole sphincter length, the whole length; proximal, distal, or full length defect). The scoring system used for 
assessment of the extension of the defects has been described in detail in a previous publication (2). A score of 0 means no defect, a score of 16 means a maximal defect.

A defect score of 1-4 was defined as a small defect, a defect score of 5-7 as a moderate defect, and a defect score of $\geq 8$ as a large defect. A change in score between two examinations of 1-3 was defined as a minor change, a change of $4-6$ as a moderate change, and a change of $\geq 7$ as a major change. Defects seen after but not before delivery were defined as 'delivery related endosonographic defects’.

\section{2:4 Anal manometry}

Anal manometry was performed using a water-perfused catheter with a $4 \mathrm{~mm}$ outer diameter and with eight sensory ports located $52 \mathrm{~mm}$ from the tip and at a distance of $45^{\circ}$ from each other (VMC-8 manometric catheter, Medtronic AB, Stockholm, Sweden). A continuous pullthrough technique with a computer-controlled stepper motor was used (hardware PC Polygraf HR, Medtronic AB, Stockholm, Sweden). The catheter withdrawal rate was $2.5 \mathrm{~mm} / \mathrm{s}$. Technically acceptable pressure curves were stored in a computer for analysis off-line using polygram for Windows, version 2.04 (Metronic AB, Stockholm, Sweden). Three measurements were performed with the anal sphincter at rest, and three measurements were performed while the patient attempted active contraction (squeeze). Resting pressure, squeeze pressure, and mean sphincter resting pressure area were calculated. Resting pressure was defined as the mean of the highest pressures at each of the eight sensory ports. The mean of three replicate measurements was used in our analyses. Squeeze pressure was defined as the highest pressure at any of the eight sensory ports. The highest squeeze pressure of three replicate measurements was used. The mean sphincter resting pressure area is the mean of eight pressure areas under the curve - one pressure area for each of the eight sensors - during continuous retraction through the sphincter at rest. We used the mean of three replicate measurements. The manometric length of the anal canal was defined as the distance from the 
start of the pressure increase during the pull-through manoeuvre with the sphincter at rest to the point at which pressure fell to zero when the catheter left the anal canal. The maximal or minimal manometric lengths were defined as the maximal and minimal length, respectively, at any of the eight sensory ports. The mean sphincter length was defined as the mean length of the eight sensory ports. The mean of three replicate measurements was used. The difference between the maximal and minimal manometric length was calculated

\section{2:4 Questionnaires}

The women answered a questionnaire with regard to bowel function (continence of gas, liquid and solid stool) and urinary incontinence at 6 months after delivery. A change in bowel function (i.e., after vs. before delivery) was specifically asked for. Anal incontinence starting after the delivery was defined as 'incontinence related to delivery'. The results of the questionnaire were expressed as a faecal incontinence score (Wexner score) (16). An incontinence score of 1 or 2 was defined as minor incontinence, a score of 3 as moderate incontinence, and a score of $\geq 4$ as major incontinence.

\section{2:5 Delivery records}

After the ultrasound images and the manometry results had been analysed, the delivery records were assessed. The following clinical information was retrieved: mode of delivery (spontaneous vaginal delivery, vacuum or forceps extraction, delivery with the aid of external pressure on the uterus), use of episiotomy, type of episiotomy, and perineal laceration.

\section{2:6 Statistics}

Intra-observer agreement with regard to presence/absence of endosonographic sphincter defects was determined using the weighted kappa statistic. The statistical significance of differences in continuous data was determined using Student's t-test for paired or unpaired data where appropriate, and that of differences in categorical data using Fisher's exact test. Bonferroni`s correction was used to correct for multiple comparisons. Linear regression 
analysis was used to determine a possible correlation between variables. The binomial distribution was used to calculate $95 \%$ exact confidence intervals (CI). P-values $\leq 0.05$ were considered statistically significant. Statistical analysis was carried out using StatView 5.0 for Windows (SAS Institute Inc., 1992-1998, Berkeley, CA, USA).

\section{Results}

\section{3:1 Clinical data}

Twenty women had a spontaneous vaginal delivery. Three women were delivered by vacuum extraction and left sided episiotomy and one woman by vacuum extraction without episiotomy. Four women were delivered with the aid of external pressure on the uterus and left sided $(\mathrm{n}=3)$ or right sided $(\mathrm{n}=1)$ episiotomy, and four women had a left sided episiotomy only. The indications for intervention were: fetal distress $(n=8)$, secondary arrest of labor $(n=3)$, or rigid perineum $(n=1)$. Twelve women had no perineal laceration, 11 women had a first degree perineal laceration, and nine women had a second degree perineal laceration.

\section{3:2 Endosonographic defects}

The kappa value for intra-observer agreement with regard to the presence of sphincter defects in the third trimester was 0.76 with disagreement in two of 32 women. The corresponding values for the post-partum examinations were 0.76 ( 2 weeks post-partum) and 0.81 (6 months post-partum) with intra-observer disagreement in 3 of 32 women at both post-partum examinations.

Results with regard to endosonographic sphincter defects are shown in Table 1. Five women (16\%; 95\% confidence interval 4.5-29.0\%) had endosonographic defects detected in the third trimester. In three of these women the defect was also visible 2 weeks and 6 months postpartum, but in two of them the defect was not detectable 2 weeks post-partum but was seen again 6 months post-partum. All five women with endosonographic defects detected before 
delivery had small defects, and only minor changes in the extension of these defects over time were seen. Eight women (25\%; 95\% CI 11-43\%) with no sphincter defects during pregnancy had defects detected post-partum. In five women with no defect detected during pregnancy an endosonographic defect was seen at both post-partum examinations. In three of these, the defect remained unchanged, in two it became larger, so that 6 months post-partum one woman had a moderate defect and one had a large defect. In three women with no visible defect either during pregnancy or 2 weeks post-partum a defect was detected 6 months after delivery. One

of these defects was large. Six of the eight (75\%) women with new endosonographic defects 6 months post-partum had undergone episiotomy vs. five of the 24 (21\%) women without new defects $(p=0.02)$. In all six women where a new defect was detected after episiotomy, the episiotomy had been performed ipsilateral to the defect. One woman with a defect in the third trimester had a new defect on the same side as her episiotomy 2 weeks after delivery, but the new defect was no longer seen 6 months post-partum (case no 35 in Table 1, Figure 1b). Two of the four women who were delivered with the aid of external pressure on the uterus had a moderate or large defect (score $\geq 7$ ) 6 months post-partum vs. only one of the 28 women delivered without external pressure $(\mathrm{p}=0.03)$.

There was no statistically significant difference between the 12 women with no clinical perineal laceration and the 20 women with a first or second degree perineal laceration with regard to the presence of new endosonographic sphincter defects 6 months post-partum (4/12 vs. $4 / 20, p=0.43)$.

\section{3:3 Results of endosonographic sphincter measurements in 19 women without} sphincter defects

Results of endosonographic sphincter measurements in the 19 women without sphincter defects are shown in Table 2. The anal sphincter was thicker and longer during pregnancy 
than 6 months post-partum, but only the difference in sphincter length was statistically significant.

\section{3:4 Anal manometry results in 19 women without sphincter defects}

Anal manometry results are shown in Table 3. Rest pressure, resting pressure area and squeeze pressure were significantly lower 2 weeks post-partum than during pregnancy, but 6 months after delivery only the resting pressure area was significantly lower than before delivery. Manometric sphincter length was significantly greater during pregnancy than 6 months post-partum. The difference between the maximum and minimum manometric lengths was also greater, but this difference was not statistically significant.

\section{3:5 Symptoms of incontinence}

Six months after delivery 16 (50\%) women reported anal incontinence (Wexner score $\geq 1$ ). The problems were minor in 12, moderate in three and major in one. Thirteen women had gas incontinence only, and three were incontinent for both gas and liquid stool. All 11 women with anal incontinence unrelated to delivery had minor incontinence vs. only one of the five (20\%) women who reported their incontinence problems to have started after delivery $(p=0.003)$. Three of the five women with delivery related problems were incontinent for gas only (score 2-3), and two were incontinent for both gas and liquid stool (score 3 and 5). Two of the five women with delivery related anal incontinence had been delivered with some intervention (external pressure on the uterus, episiotomy, or vacuum extraction) vs. 10 of the 27 women without delivery related anal incontinence $(\mathrm{p}>0.99)$.

\section{3:6 Correlation between endosonographic defect score and sphincter pressure}

There was no correlation between endosonographic sphincter defect score and sphincter pressure either during pregnancy or post-partum $\left(r^{2}=0.01-0.06\right.$; $\left.p=0.17-0.75\right)$.

\section{3:7 Correlation between endosonographic sphincter length and manometric} sphincter length 
There was no correlation between endosonographic sphincter length and manometric sphincter length either in the third trimester of pregnancy or post-partum $\left(r^{2}=0.01-0.12\right.$; $\mathrm{p}=0.06-0.86)$

\section{3:8 Correlation between endosonographic defect score and Wexner incontinence score}

There was no correlation between endosonographic defect score at 2 weeks after delivery and the Wexner incontinence score. This was true even when only those women who became incontinent after delivery were considered incontinent, and when only those women with new endosonographic defects after delivery were considered to have defects (four correlation coefficients calculated). However, there was a statistically significant positive correlation between the endosonographic defect score at 6 months and Wexner incontinence score $\left(r^{2}=\right.$

$0.27, \mathrm{p}=0.002$; Figure 2 ). The positive correlation remained statistically significant and $\mathrm{r}$ values and p-values remained virtually unchanged when only those women who became incontinent after delivery were considered incontinent, and when only those women with new endosonographic defects after delivery were considered to have defects (another three correlation coefficients calculated)

\section{3:9 Correlation between sphincter pressure and Wexner incontinence score}

There was a negative correlation between rest pressure at 2 weeks after delivery and Wexner incontinence score $\left(r^{2}=0.23, p=0.006\right)$. This negative correlation was explained by one single woman who had a low rest pressure $(54 \mathrm{mmHg})$ and a high incontinence score (score 5). No correlation was seen between sphincter pressure 6 months after delivery and Wexner incontinence score. 


\section{Discussion}

In the present study five (16\%) of the 32 pregnant women who had never given birth had an endosonographic sphincter defect. Other research teams found no defects $(3,6,9,11)$, or external sphincter defects in $10 \%$ and internal sphincter defects in $5 \%$ of asymptomatic nonpregnant nullipara (17). The fact that small sphincter defects are relatively common in asymptomatic women who have never given birth questions the reliability of anal endosonography and the clinical significance of small sphincter defects. Small endosonographic defects might be a normal variant, or the result of non-obstetric trauma. In parous women they may be - correctly or incorrectly - attributed to childbirth.

Faltin and coworkers found endosonographic defects in $28 \%$ of 150 primiparous women examined by endosonography immediately after a vaginal delivery, where no anal sphincter laceration had been detected clinically. However, they did not examine the women before delivery, and so they do not know how many of the defects were likely to be explained by birth trauma (18). In our study, all the five small defects that we had seen during pregnancy were virtually unchanged 6 months after delivery. These small post-delivery defects almost certainly had nothing to do with the vaginal delivery.

A meta-analysis of 717 vaginal deliveries revealed a 26.9\% prevalence of endosonographic anal sphincter defects in primiparous women and an 8.5\% prevalence of new defects in multiparous women. The size of these sphincter defects was not commented on, but at least two-thirds of the women with occult defects were asymptomatic post-partum (19). The introduction of our endosonographic defect scoring system facilitates the study of a possible association between the size of sphincter defects and anal incontinence. Most of the defects $(5 / 8)$ that arose after delivery in our study were small (score $3-4)$ and might have been clinically irrelevant, because none of these small defects was associated with delivery related 
anal incontinence. Only two women (2/32 = 6\%; 95\% confidence interval 0.8-20.8\%) had developed a large defect 6 months post partum. Both had delivery related anal incontinence. To the best of our knowledge a possible association between episiotomy and endosonographic sphincter defects has been examined in only one study (20). In that study all episiotomies were right medio-lateral, but sonography showed a predominance of left-sided sphincter scarring (which we presume is equivalent to left-sided sphincter damage). A plausible explanation was not suggested by the authors. Midline episiotomy is a risk factor for clinical third and fourth degree perineal lacerations, $(21,22)$. In our institution, left-lateral episiotomy is standard, if episiotomy is judged to be necessary. Six of the eleven women in our study who had an episiotomy had a delivery related endosonographic defect at 6 months, all being located on the same side as the episiotomy. It is possible, that at least some of these defects were caused by or facilitated by the episiotomy itself. The higher rate of delivery related endosonographic sphincter defects among women undergoing episiotomy is not surprising, because episiotomy is used in women judged to be at risk of perineal laceration or in conjunction with instrumental delivery, which may predispose to perineal tears. Uterine pressure also seemed to be a risk factor, because it was associated with increased risk of moderate or large sonographic defects 6 months post-partum. Our material is too small to allow determination of with factor is most strongly associated with delivery related endosonographic anal sphincter defects in women with clinically unrecognized anal sphincter tear: episiotomy, uterine pressure, or other obstetric interventions. Nonetheless, our results suggest that women who have an episiotomy are at higher risk than those who have not of having a sonographic anal sphincter defect, and that women delivered with the assistance of uterine pressure are at higher risk of larger defects. In agreement with other research teams we found sphincter pressure to decrease soon after delivery $(3,4,8,10)$, but to have recovered after 6 months. Our results suggest that the anal sphincter is longer during pregnancy than in 
the non-pregnant state (statistically significant difference), and that it may be slightly thicker (non-significant difference). The results of one of our previous studies, where we compared pregnant women to non-pregnant women of the same age point in the same direction: the anal sphincter was thicker and manometric sphincter length was greater in pregnant women (12). Possibly, the changes in anal sphincter size during pregnancy are explained by hormonal effects on the sphincter (23).

At 6 months post-partum there was a positive correlation between endosonographic sphincter defect score and Wexner incontinence score. This positive correlation is likely to be explained by two women with high endosonographic defect scores and high incontinence scores. Only four women had moderate or major incontinence, and only three women had a moderate or major endosonographic sphincter defect. The true magnitude of the correlation between defect score and incontinence score cannot be estimated with any precision on the basis of the results of our study.

Our study has the limitation of being small. This is explained by the difficulty of recruiting healthy asymptomatic volunteers to our study and to motivate them to return for both their post-partum examinations. The small size of our study means that some associations or correlations might have gone undetected (for instance a possible correlation between sphincter pressure and anal sphincter defect score), and that confidence intervals for prevalences are wide. However,we did find some statistically significant associations, e.g., that between episiotomy and delivery related anal sphincter defects and between uterine pressure and large delivery related anal sphincter defects. A second limitation of our study is that because the volunteers answered a questionnaire about anal incontinence only after delivery - but not during pregnancy - any changes in incontinence symptoms reported are based solely on the women's memory. This makes our definition of delivery related incontinence somewhat uncertain. 
To sum up, our results confirm those of others that small endosonographic anal sphincter defects are common in nulliparous women in the third trimester of pregnancy, and that new endosonographic sphincter defects may arise after a vaginal delivery where no anal sphincter tear was detected clinically. Most defects in our pregnant nullipara were small and located proximally and anteriorly, and so were most occult defects that arose after delivery. Women with small defects seemed to have no or only minor problems with anal incontinence 6 months post partum. Thus, small endosonographic sphincter defects may be clinically unimportant, at least in a short-term perspective. On the other hand we found that the larger the endosonographic defect the higher the incontinence score at 6 months, and we found an association between uterine pressure and large delivery related endosonographic anal sphincter defects. This leads us to caution against the use of uterine pressure to expedite delivery.

\section{Acknowledgement}

The study was supported by a governmental grant (Landstingsfinansierad regional forskning, Skåne, Sweden), a grant from the Department of Surgery, Malmö University Hospital, Malmö, Sweden, and Einar and Inga Nilssons private grant for surgical research. 


\section{References}

[1] Sultan AH, Kamm MA, Hudson CN, Bartram CI. Third degree obstetric tears: Risk factors and outcome of primary repair. BMJ 1994;308:887-91.

[2] Starck M, Bohe M, Valentin L. Results of anal endosonographic imaging of the analsphincter 2-7 days after primary repair of third or fourth degree obstetric sphincter tears. Ultrasound Obstet Gynecol 2003;22:609-15

[3] Sultan AH, Kamm MA, Hudson CN, Thomas JM, Bartram CI. Anal-sphincter disruption during vaginal delivery. N Engl J Med 1993;329:1905-11.

[4] Rieger N, Schloithe A, Saccone G, Wattchow D. A prospective study of anal injury due to childbirth. Scand J Gastroenterol 1998;33:950-5.

[5] Varma A, Gunn J, Gardiner A, Lindow SW, Duthie GS. Obstetric anal sphincter injury: prospective evaluation of incidence. Dis Colon Rectum 1999;42:1537-43.

[6] Abramowitz L, Sobhani I, Ganansia R, Vuagnat A, Benifla JL, Darai E, Madelenat P, Mignon M. Anal sphincter defects the cause of anal incontinence after vaginal delivery? Results of a prospective study. Dis Colon Rectum 2000;43:590-8.

[7] Williams AB, Bartram CI, Halligan S, Spencer JA, Nicholls RJ, WA. Anal sphincter damage after vaginal delivery using three-dimensional endosonography. Obstet Gynecol 2001;97:770-5.

[8] Faridi A, Willis S, Schelzig P, Siggelkow W, Schumpelick V, Rath W. Anal sphincter injury during vaginal delivery - argument for cesarean section on request? J Perinat Med 2002;30:379-87.

[9] Nazir M, Carlsen E, Nesheim B-I. Do occult anal sphincter injuries, vector volume manometry and delivery variables have any predictive value for bowel symptoms after first time vaginal delivery without third and fourth degree rupture? A prospective study. Acta Obstet Gynecol Scand 2002;81:720-6. 
[10] Willis S, Faridi A, Schelzig S, Hoelzl F, Kasperk R, Rath W, Schumpelick V. Childbirth and incomtinence: a prospective study on anal sphincter morphology and function before and early after vaginal delivery. Langenbeck’s Arch Surg 2002;387:101-7.

[11] Zetterström J, Mellgren A, Jensen LL, Wong WD, Kim DG, Lowry AC, Madoff RD, Congilosi SM. Effect of delivery on anal sphincter function. Dis Colon Rectum 1999;42:1253-60.

[12] Starck M, Bohe M, Fortling B, Valentin L. Endosonography of the anal sphincter in women of different ages and parity. Ultrasound Obstet Gynecol 2005;25:169-76.

[13] Sultan AH, Kamm MA, Hudson CN, Bartram CI. Effect of pregnancy on anal morphology and function. Int J Colorect Dis 1993;8:206-9.

[14] Frudinger A, Halligan S, Bartram CI, Spencer JA, Kamm MA. Changes in anal anatomy following vaginal delivery revealed by anal endosonography. Br J Obstet Gynaecol 1999;106:233-7.

[15] Williams AB, Bartram CI, Halligan S, Marshall MM, Spencer JAD, Nicholls RJ, Kmiot WA. Alteration of anal sphincter morphology following vaginal delivery revealed by multiplanar anal endosonography. Br J Obstet Gynaecol 2002;109:942-6.

[16] Jorge JMN, Wexner SD. Etiology and management of fecal incontinence. Dis Colon Rectum 1993;36:77-97.

[17] Sentovich SM, Blatchford GJ, Rivela LJ, Lin K, Thorson AG, Christensen MA. Diagnosing anal sphincter injury with transanal ultrasound and manometry. Dis Colon Rectum 1997;40:1430-4.

[18] Faltin DL, Boulvain M, Irion O, Bretones S, Stan C, Weil A. Diagnosis of anal sphincter tears by postpartum endosonography to predict fecal incontinence. Obstet Gynecol 2000;95:643-7. 
[19] Oberwalder M, Connor J, Wexner SD. Meta-analysis to determine the incidence of obstetric anal sphincter damage. Br JSurg 2003;90:1333-7.

[20] Frudinger A, Bartram CI, Spencer JAD, Kamm CI. Perineal examination as a predictor of underlying external anal sphincter damage. Br J Obstet Gynaecol 1997;104:1009-13.

[21] Jander C, Lyrenas S. Third and fourth degree perineal tears. Predictor factors in a referral hospital. Acta Obstet Gynecol Scand 2001;80:229-34.

[22] Bodner-Adler B, Bodner K, Kaider A, Wagenbichler P, Leodolter S, Husslein P, Mayerhofer K. Risk factors for third-degree perineal tears in vaginal deliver with an analysis of episiotomy types. J Reprod Med 2001;46:752-6.

[23] Haadem K, Ling L, Ferno M, Graffner H.Estrogen receptors in the external anal sphincter. Am J Obstet Gynecol 1991;164:609-10. 
Table 1. Endosonographic sphincter defects, mode of delivery, and Wexner incontinence score

\begin{tabular}{|c|c|c|c|c|c|c|c|c|}
\hline $\begin{array}{l}\text { Case } \\
\text { No }\end{array}$ & \multicolumn{2}{|c|}{ 3rd trimester } & $\begin{array}{l}\text { Mode of } \\
\text { delivery }\end{array}$ & \multicolumn{2}{|c|}{2 weeks post-partum } & \multicolumn{2}{|c|}{6 months post-partum } & $\begin{array}{c}\text { Wexnel } \\
\text { score }\end{array}$ \\
\hline 35 & $\begin{array}{l}\text { PTE, <half length, } \\
10 \text { o'clock, } 30^{\circ}\end{array}$ & 4 & $\mathrm{VE}+\mathrm{POS}$ & $\begin{array}{l}\text { PPE, > half length, } \\
10 \text { o'clock, } 30^{\circ} \text {, and } \\
\text { PTE, > half length, } \\
1 \text { o'clock, } 30^{0}\end{array}$ & 6 & $\begin{array}{l}\text { PPE, > half length, } \\
10 \text { o'clock, } 30^{\circ}\end{array}$ & 4 & $0(0)$ \\
\hline 46 & $\begin{array}{l}\text { PTE, <half length, } \\
10 \text { o'clock, } 45^{\circ}\end{array}$ & 4 & Spont & $\begin{array}{l}\text { PTE, } \leq \text { half length, } \\
10 \text { o'clock, } 45^{\circ}\end{array}$ & 4 & $\begin{array}{l}\text { PTE, <half length, } \\
10 \text { o'clock, } 45^{\circ}\end{array}$ & 4 & $1(0)$ \\
\hline 17 & $\begin{array}{l}\text { PPE, <half length, } \\
10 \text { o'clock, } 30^{0}\end{array}$ & 3 & Press+POS & No defect & 0 & $\begin{array}{l}\text { PPE, } \leq \text { half length, } \\
10 \text { o'clock, } 30^{\circ} \text {, and } \\
\text { PPE, } \leq \text { half length, } \\
12 \text { o'clock, } 30^{\circ}\end{array}$ & 4 & $0(0)$ \\
\hline 1 & No defect & 0 & Press + POS & $\begin{array}{l}\mathrm{PPE}, \leq \text { half length, } \\
12 \text { o'clock, } 60^{\circ}\end{array}$ & 3 & $\begin{array}{l}\mathrm{PPE}, \leq \text { half length, } \\
1 \text { o'clock, } 30^{\circ}\end{array}$ & 3 & $1(0)$ \\
\hline 2 & No defect & 0 & Spont & $\begin{array}{l}\text { PTE, <half length, } \\
1 \text { o'clock, } 30^{\circ}\end{array}$ & 4 & $\begin{array}{l}\text { PTE, <half length, } \\
1 \text { o'clock, } 30^{0}\end{array}$ & 4 & $1(0)$ \\
\hline
\end{tabular}


Table 1. Cont.

\begin{tabular}{|c|c|c|c|c|c|c|c|c|}
\hline \multirow{2}{*}{\begin{tabular}{|c|} 
Case \\
No
\end{tabular}} & \multicolumn{2}{|c|}{ 3rd trimester } & \multirow{2}{*}{$\begin{array}{l}\text { Mode of } \\
\text { delivery }\end{array}$} & \multicolumn{2}{|c|}{2 weeks post-partum } & \multicolumn{3}{|c|}{6 months post partum } \\
\hline & Description & $\begin{array}{c}\text { Defect } \\
\text { score }\end{array}$ & & Defect score & $\begin{array}{c}\text { Defect } \\
\text { score }\end{array}$ & Description & $\begin{array}{c}\text { Defect } \\
\text { score }\end{array}$ & $\begin{array}{c}\text { Wexner } \\
\text { score }\end{array}$ \\
\hline 15 & No defect & 0 & $\mathrm{VE}+\mathrm{POS}$ & $\begin{array}{l}\text { PTE, } \leq \text { half length, } \\
1 \text { o'clock, } 30^{0}\end{array}$ & 4 & $\begin{array}{l}\text { PTE, } \leq \text { half length, } \\
1 \text { o'clock, } 30^{\circ}\end{array}$ & 4 & $0(0)$ \\
\hline 40 & No defect & 0 & Press+PODx & $\begin{array}{l}\text { PPE, >half length, } \\
11 \text { o'clock, } 75^{0}\end{array}$ & 4 & 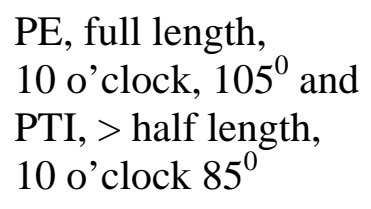 & 11 & $3(3)$ \\
\hline 43 & No defect & 0 & Press+POS & $\begin{array}{l}\text { PE, full length, } \\
10 \text { o'clock, } 75^{0}\end{array}$ & 5 & $\begin{array}{l}\text { PE, full length, } \\
10 \text { o'clock, } 30^{0} \text {, and } \\
\text { TE, full length, } \\
1 \text { o'clock, } 30^{\circ}\end{array}$ & 7 & $1(0)$ \\
\hline 16 & No defect & 0 & Spont & No defect & 0 & $\begin{array}{l}\text { PPE, } \leq \text { half length, } \\
10 \text { o'clock, } 30^{\circ}\end{array}$ & 3 & $0(0)$ \\
\hline 22 & No defect & 0 & POS & No defect & 0 & $\begin{array}{l}\text { PTE, } \leq \text { half length, } \\
12 \text { o'clock, } 45^{0}\end{array}$ & 4 & $1(0)$ \\
\hline 31 & No defect & 0 & POS & No defect & 0 & $\begin{array}{l}\text { PPE, >half length, } \\
10 \text { o'clock, } 45^{\circ} \text {, and } \\
\text { TI, full length, } \\
11 \text { o'clock, } 75^{0}\end{array}$ & 10 & $5(5)$ \\
\hline
\end{tabular}

( ) = score for incontinence related to delivery 
Mode of delivery: Spont = spontaneous vaginal delivery, POS = perineotomia obliqua sinister, $\mathrm{PODx}=$ peritoneotomia obliqua dexter, $\mathrm{VE}=$ vacuum extraction, Press = delivery with the aid of external pressure on the uterus

Description of anal sphincter defects: PPE = proximal partial external defect, PTE = proximal total external defect, $\mathrm{PE}=$ partial external defect, $\mathrm{TE}=$ total external defect, $\mathrm{PTI}=$ proximal total internal defect, $\mathrm{TI}=$ total internal defect

The extension of a defect is described using a clockwork symbol. The 'time' indicates the start of the defect, and the degrees indicate the clockwise extension of the defect. 
Table 2. Results of endosonographic sphincter measurements in 19 women without sphincter defects

\begin{tabular}{|c|c|c|c|}
\hline & $\begin{array}{c}\text { 3rd } \\
\text { trimester }\end{array}$ & $\begin{array}{c}2 \text { weeks } \\
\text { post partum }\end{array}$ & $\begin{array}{l}6 \text { months } \\
\text { post partum }\end{array}$ \\
\hline \multicolumn{4}{|l|}{ Sphincter thickness mm;mean_SD } \\
\hline \multicolumn{4}{|l|}{ External sphincter } \\
\hline 12 o’clock & $5.4 \pm 0.62$ & $5.6 \pm 0.76$ & $5.3 \pm 0.55$ \\
\hline 3 o’clock & $6.0 \pm 0.88$ & $6.0 \pm 1.47$ & $5.8 \pm 0.92$ \\
\hline 6 o’clock & $6.6 \pm 1.02$ & $6.6 \pm 1.06$ & $6.4+1.30$ \\
\hline 9 o’clock & $6.6 \pm 1.03$ & $6.3 \pm 1.13$ & $6.0 \pm 1.06^{*}$ \\
\hline mean of four measurements & $6.2 \pm 0.62$ & $6.2 \pm 0.84$ & $5.9 \pm 0.60$ \\
\hline \multicolumn{4}{|l|}{ Internal sphincter } \\
\hline 12 o’clock & $1.7 \pm 0.57$ & $1.5 \pm 0.47$ & $1.5 \pm 0.55$ \\
\hline 3 o’clock & $1.9+0.58$ & $1.7+0.68$ & $1.6+0.61$ \\
\hline 6 o’clock & $2.0+0.69$ & $2.0+0.84$ & $1.7 \pm 0.64$ \\
\hline 9 o’clock & $2.4+0.50$ & $2.5+0.73$ & $2.3+0.60$ \\
\hline mean of four measurements & $2.0+0.36$ & $2.0+0.49$ & $1.8+0.39$ \\
\hline \multicolumn{4}{|l|}{ Sphincter length, mm; mean+SD } \\
\hline posterior & $31.6 \pm 2.67$ & $31.1+2.82$ & $29.9+2.61^{*}$ \\
\hline anterior & $26.5+2.78$ & $25.2 \pm 3.04$ & $23.9+3.06^{* *}$ \\
\hline mean of the posterior and anterior lengths & $29.3 \pm 2.71$ & $28.1 \pm 2.82$ & $27.1 \pm 2.70^{*}$ \\
\hline $\begin{array}{r}\text { difference between the posterior and } \\
\text { anterior lengths }\end{array}$ & $5.4+1.54$ & $5.9 \pm 2.36$ & $6.0 \pm 1.56$ \\
\hline
\end{tabular}

$\mathrm{SD}=$ standard deviation. 
* p-value $\leq 0.05 * *$ p-value $\leq 0.01$ (p-values after Bonferroni correction). The asterisks refer to comparisons made with results obtained in the third trimester. 
Table 3. Anal manometry results in 19 women without sphincter defects

\begin{tabular}{|c|c|c|c|}
\hline & 3rd trimester & $\begin{array}{c}2 \text { weeks } \\
\text { post partum }\end{array}$ & $\begin{array}{c}6 \text { months } \\
\text { post partum }\end{array}$ \\
\hline \multicolumn{4}{|l|}{ Sphincter pressure, mean+SD } \\
\hline rest pressure, mmHg & $108+32.2$ & $86 \pm 19.3^{* *}$ & $98+28.1$ \\
\hline resting pressure area, mmHgxmm & $2696+1019$ & $1994+554^{* *}$ & $2235+680 *$ \\
\hline squeeze pressure, mmHg & $188 \pm 44.1$ & $154 \pm 30.6 *$ & $172 \pm 47.4$ \\
\hline \multicolumn{4}{|l|}{ Sphincter length mm; mean+SD } \\
\hline maximum & $53.5+4.18$ & $51.5+5.18$ & $50.7 \pm 3.74 *$ \\
\hline minimum & $47.0 \pm 4.03$ & $44.5+5.19$ & $44.2 \pm 3.86 *$ \\
\hline mean & $50.0 \pm 3.61$ & $48.4+5.05$ & $47.5 \pm 3.73 *$ \\
\hline $\begin{array}{l}\text { difference between maximum and } \\
\text { minimum length }\end{array}$ & $6.5 \pm 3.13$ & $5.9+2.36$ & $6.0 \pm 1.56$ \\
\hline
\end{tabular}

$\mathrm{SD}=$ standard deviation.

* p-value $\leq 0.05 * *$ p-value $\leq 0.01$ ( $\mathrm{p}$-values after Bonferroni correction). The asterisks refer to comparisons made with results obtained in the third trimester. 


\section{Legends}

Figure 1.Images of a normal and a defect sphincter. Ultrasound image to the left, schematic drawing to the right a) Ultrasound image of a normal anal canal. The external sphincter is hyperechoic, the internal sphincter is hypoechoic, the anal mucosa is hyperechoic b) A partial external sphincter defect starting at 10 o'clock and extending $30^{\circ}$ and a total external sphincter defect starting at 1 o'clock and extending $30^{\circ}$ (arrow). This woman had a left episiotomy performed, and only the defect starting at 10 o'clock was seen during pregnancy, whereas both defects were seen 2 weeks post-partum (case no 35 in Table 1).

Figure 2. Correlation between the endosonographic sphincter defect score and Wexner incontinence score in 32 women. The statistically significant positive correlation $\left(r^{2}=0.27\right.$, $\mathrm{p}=0.002$ ) is explained by two women with high endosonographic defect score and high incontinence score. 


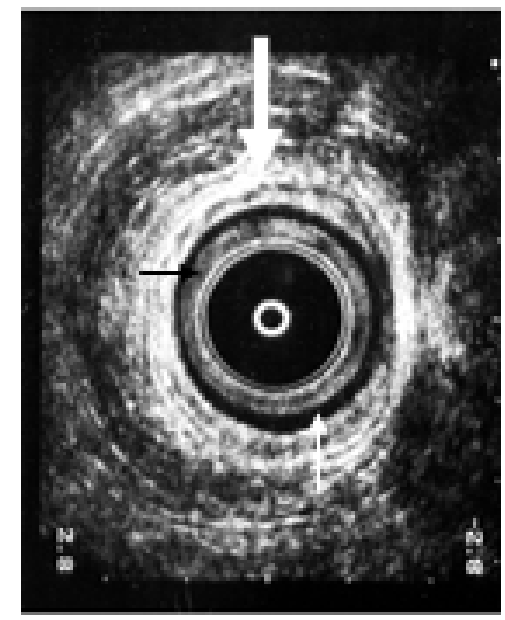




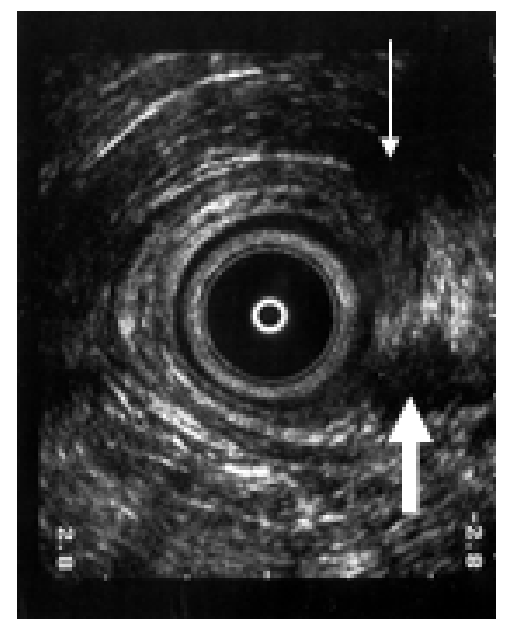

